\title{
Evaluating the Effects of Rumenocentesis on Health and Performance in Dairy Cows
}

\author{
Matteo Gianesella ${ }^{1}$, Massimo Morgante ${ }^{1}$, Calogero Stelletta $^{1}$, Licia Ravarotto ${ }^{2}$, \\ Elisabetta Giudice ${ }^{3}$, Robert J. Van Saun ${ }^{4}$ \\ ${ }^{1}$ Department of Veterinary Clinical Sciences, University of Padua, Legnaro, Italy \\ ${ }^{2}$ Istituto Zooprofilattico Sperimentale delle Venezie, Legnaro, Italy \\ ${ }^{3}$ Department of Veterinary Public Health, University of Messina, Messina, Italy \\ ${ }^{4}$ Department of Veterinary and Biomedical Sciences, Pennsylvania State University, Pennsylvania, USA
}

Received March 4, 2009

Accepted March 8, 2010

\begin{abstract}
The objective of this study was to evaluate the effects of the rumenocentesis procedure on dairy cows by determining selected metabolic and physiological variables representing the health status. Two groups of 6 cows either underwent rumenocentesis (GA) or sham (GB) procedures. Superficial skin temperature of the rumenocentesis area was measured using infrared thermography before the procedure $(-1 \mathrm{~h})$, immediately after $(0 \mathrm{~h})$, and at $48 \mathrm{~h}, 96 \mathrm{~h}$, and 20 days following rumenocentesis. Blood samples were collected at all times, except for immediately after the procedure $(0 \mathrm{~h})$, and selected immunologic response variables were determined. Milk yield and rectal temperatures were measured daily. Rumenocentesis did not influence the white blood cell count, haptoglobin or total protein concentrations. Electrophoretic protein fractions were not different between GA and GB treatments. Milk yield and rectal temperature were not affected by rumenocentesis. Skin temperature of the rumenocentesis region in GA group cows increased by $1.0{ }^{\circ} \mathrm{C}$ immediately after rumenocentesis and returned to baseline after $48 \mathrm{~h}$ where it remained constantly until the end of the study; similar to observation in GB group cows. Results of this study would suggest minimal adverse effects on cow health and production when performing rumenocentesis for the diagnosis of subacute ruminal acidosis. Additional more intensive studies addressing animal welfare issues relative to the diagnostic techniques are needed.
\end{abstract}

Health, infrared thermography, welfare

Scientific interest in animal health and welfare has increased greatly in recent years (Rollin 1990; Thompson 2005; Lusk and Norwood 2008). Many scientists agree that animal health and welfare involve subjective assessment of animal well-being; however, more objective evaluations are necessary. Welfare status can be adversely affected by negative stimuli such as pain, disease, and fear. Human handling, such as during diagnostic testing procedures, could induce pain and fear responses. Therefore, it is appropriate to investigate diagnostic techniques for their potential to adversely affect animal health and welfare relative to the benefit of obtaining diagnostic results.

Subacute rumen acidosis (SARA) is one of the most important health disorders affecting dairy cows, adversely influencing rumen fermentation, animal welfare (i.e., lameness risk), productivity, and farm profitability (Krause and Oetzel 2006). Dairy cows experiencing clinical ruminal acidosis are characterized by prolonged bouts of abnormally low rumen fluid $\mathrm{pH}(<5.0)$, whereas SARA is typically defined as intermittent declines in rumen fluid $\mathrm{pH}$ below 5.5 units. Both clinical acidosis and SARA are generally induced by excessive consumption of dietary nonstructural carbohydrates (NSC) resulting in excessive production of volatile fatty acids and lactic acid, further resulting in ruminal fluid $\mathrm{pH}$ decline. Dietary and feeding management factors that influence feed sorting behaviour result in cows consuming a diet with an effective increase in dietary NSC content coupled with decreased consumption of physically effective fibre, thus predisposing to the abnormal rumen fermentation patterns leading to the acidosis condition. It is commonly believed that

Address for correspondence:

Matteo Gianesella

Department of Veterinary Clinical Sciences

University of Padua, Viale dell'Università 16

35020, Legnaro (PD), Italy
Phone: +390498272942

Fax: +390498272954

E-mail: matteo.gianesella@unipd.it

http://www.vfu.cz/acta-vet/actavet.htm 
SARA is under-diagnosed because of lack of pathognomonic signs, diurnal fluctuations in rumen $\mathrm{pH}$, and problems obtaining representative rumen fluid samples (Jorgenson et al. 1993; Nordlund and Garrett 1994). The determination of ruminal $\mathrm{pH}$ is a key factor for the diagnosis of SARA (Ennemark et al. 2002). Common field techniques for collecting rumen fluid for SARA diagnosis include rumenocentesis using percutaneous needle aspiration (Nordlund and Garrett 1994), and oral stomach tube (Nocek 1997). Rumenocentesis is reported to be superior to the use of an oral stomach tube for rumen $\mathrm{pH}$ determination as the latter technique is susceptible to salivary contamination, thus increasing the sample $\mathrm{pH}$ (Nordlund and Garrett 1994; Garret et al. 1999; Duffield et al. 2004).

Opinions relative to potential risks associated with the ruminocentesis procedure are controversial. Some authors (Hollberg 1984; A ce to et al. 2000; Strabel at al. 2007) consider rumenocentesis an invasive technique with potentially serious complications. Consequently, veterinary practitioners may consider the procedure to be too difficult to use during clinical investigations. Nordlund and Garrett (1994) recognized rumenocentesis as being invasive with potential secondary complications of peritonitis, abdominal and ruminal wall abscessation, and injury due to the necessary restraint. Although these complications would be considered endangering to animal health and welfare, they reported only a $1-2 \%$ incidence of subcutaneous abscess formation. Kleen et al. (2004) reported a 5.5\% abscess incidence in their study population. Duffield et al. (2004) described nodules (1 to $2 \mathrm{~cm}$ in diameter) at the puncture site after rumenocentesis in one third of the tested animals. Other alterations, local or general, have not been observed. Animal welfare evaluation, however, still remains a controversial and difficult argument in applying this diagnostic procedure. Scientists suggest that measures based on biological function and the ability to cope with the environment (for example by thermoregulation) provide relevant information on animal health and welfare.

Infrared thermography (IRT) is a non-invasive technique capable of detecting thermal radiation from the surface of any object (Eddy et al. 2001). In animals, body surface temperature is a function of blood flow and metabolic rate of underlying tissues. Thus, the physiological state of underlying cells could potentially be assessed by measuring skin temperature using IRT (Eddy et al. 2001). Infrared thermography and potential veterinary applications for this imaging technique have been described (Spire et al. 1999; Eddy et al. 2001; Turner 2001). These reports mostly described thermographic imaging of spontaneous disease and attempts to correlate images to disease or injury diagnosed by other means. A study in cattle revealed successful utilization of thermography in the detection of localized sepsis in the pinna after contaminated growth stimulant pellets had been administered (Spire et al. 1999). Infrared thermography has been used to predict changes in udder temperature (Berry et al. 2003) and to detect inflammation associated with hotiron and freeze branding in cattle (Schwartzkopf-Genswein and Stookey 1997), and bovine viral diarrhea infection in calves (Schaefer et al. 2004). Soles of hooves affected by subclinical laminitis commonly appear soft and warm long before the appearance of yellowish discoloration, lesions, and ulcers (Nocek 1997). The objective of the study was to evaluate the effect of rumenocentesis by percutaneous needle aspiration on the health, welfare status, and production of lactating dairy cows by assessing alterations of blood variables, milk production, and superficial skin temperature at the rumenocentesis site.

\section{Materials and Methods}

Animals

Twelve multiparous (third lactation and greater) Holstein dairy cows from a commercial herd in which prevalence of SARA was highly suspected were used in this experiment. Using the classification scheme proposed by Nordlund and Garrett (1994), this herd had a high risk for SARA as more than 33\% of the sampled cows had rumen $\mathrm{pH}<5.5$. Dietary evaluation suggested a high risk for SARA based on composition and potential for feed ingredient sorting. The steaming-up and early lactation diets contained (all values on dry matter basis) 40.77 
and $30.17 \%$ neutral detergent fibre (NDF), 34.17 and $38.81 \%$ non fibre carbohydrates (NFC), and 14.7 and $28.5 \%$ starch, respectively.

Cows selected for the study were without signs of clinical disease, had high average milk production (about $10,000 \mathrm{~kg}$ per year), and good body condition score (BCS). Mean BCS ( \pm standard deviation) was $3.00 \pm 0.25$ (1 to 5 scale) according the procedure of Edmonson et al. (1989). Cows were housed in free stalls and fed a total mixed ration (TMR). All cows were between 31 and 48 days in milk (DIM) at study initiation and were fed the same diet for the study duration with a steam-up diet in the final part of the dry period.

Experimental design

Selected cows were randomly divided to 2 groups of 6 cows. Days in milk were equally balanced between the two cow groups ( 38 vs. 37.2, $P>0.7$ ). All cows in both groups underwent shearing by electric clipper (Kruuse, ca. n. 247070) and triple manual disinfection of the proposed rumenocentesis site in preparation for the rumenocentesis puncture. The group of cows then had rumenocentesis (GA) performed while the control group of cows (GB) did not have rumenocentesis performed. Rumenocentesis was performed as described by Morgante et al. (2007) without sedation, using a 13 ga $105 \mathrm{~mm}$ needle. The cow's response to rumenocentesis or sham procedure was monitored from just prior (-1 h, reference time) to 20 days following the procedure.

A physical examination of each cow was performed at $48 \mathrm{~h}, 96 \mathrm{~h}$, and 20 days after rumenocentesis. Daily milk yield and rectal temperatures were determined at each observation time period. Blood samples were collected at $-1 \mathrm{~h}, 48 \mathrm{~h}$, $96 \mathrm{~h}$, and 20 days (relative to procedure application) from a jugular vein into EDTA and lithium heparin containing tubes and vacutainer tubes without anticoagulant (BD Vacutainer Systems ${ }^{\circledR}$, Preanalytical Solutions, Belliver Industrial Estate, Plymouth, UK). Blood samples without anticoagulant and with lithium heparin were centrifuged at $2500 \times g$ at $4{ }^{\circ} \mathrm{C}$ for $20 \mathrm{~min}$, and serum and plasma were collected and frozen $\left(-20^{\circ} \mathrm{C}\right)$ until further analysis.

Skin surface temperature at the rumenocentesis site was measured prior to $(-1 \mathrm{~h})$, immediately after ( 0 time), and at $48 \mathrm{~h}, 96 \mathrm{~h}$, and 20 days after rumenocentesis. All images were scanned using a hand-held portable infrared camera (Flir System, Model ThermaCam P25), which was calibrated to ambient temperature and absorptive conditions on each sampling day. The emissivity value settled on the camera before conducting the scanning was 0.93 . To reduce the effects of environmental factors on thermal data, all images were scanned within the barn and at the same distance $(1 \mathrm{~m})$ from the subject. Temperatures were recovered by processing the thermographic images of a squared area located in the area of rumenocentesis, described by Nordlund and Garret (1994). All thermographic images were analyzed for average and maximal temperature by ThermaCam Researcher Basic Software (Flir System).

Laboratory assays

Within $2 \mathrm{~h}$ of collection, EDTA-blood was analyzed for white (WBC) and red (RBC) blood cell counts, differential WBC count (neutrophils, lymphocytes, monocytes, eosinophils, and basophils), haemoglobin $(\mathrm{Hb})$, haematocrit $(\mathrm{Hct})$, mean corpuscular volume $(\mathrm{MCV})$, mean corpuscular haemoglobin $(\mathrm{MCH})$, mean corpuscular haemoglobin concentration (MCHC), total platelet count (PLT), and mean platelet volume (MPV) using automated equipment (Abbott Cell Dyn 3500, Abbott Diagnostic Division, CA, USA). Harvested plasma samples were analyzed for a range of clinical chemistry variables creatinine, aspartate transaminase (AST), albumin, total protein, $\gamma$-glutamyl transferase $(\gamma \mathrm{GT})$, calcium, phosphorus, magnesium, sodium, potassium, chloride, glucose, cholesterol, triglycerides, non-esterified fatty acids (NEFA), total bilirubin, direct and indirect bilirubin using an automated analyzer (BM Hitachi 911, ROCHE, Basel, Switzerland). Total protein in serum was determined by automated analyzer (BM Hitachi 911, ROCHE, Basel, Switzerland). Albumin and globulin, alpha-1, alpha-2, beta-1, beta-2, and gamma were determined from serum samples by electrophoresis. Albumin to globulin ratio $(\mathrm{A} / \mathrm{G})$ was calculated from these data. The electrophoretic protein separation in $0.8 \%$ agar gel was obtained using a semiquantitative and multiparametric analyzer (Hydrasis LC, SEBIA, Issy-les-Moulineaux, France) provided with specific Phoresis software. Haptoglobin was determined by manual method measuring the spectrophotometric peroxidase activity of free haemoglobin (Phase ${ }^{\mathrm{TM}}$ Range, Haptoglobin Assay, Tridelta Development Limited, Bray, County Wicklow, Ireland).

Statistical analysis

Data obtained were analyzed by ANOVA for repeated measures to verify the effect of rumenocentesis using the Proc Mixed procedure of SAS (Littell et al. 1999). All dependent variables measured over time periods were evaluated using the following model:

$\mathrm{Y}_{\mathrm{ijk}}=\mathrm{m}+$ Treatment $_{\mathrm{i}}+$ Time $_{\mathrm{i}}+\left(\right.$ Treatment $\times$ Time $_{\mathrm{ij}}+\mathrm{e}_{\mathrm{ijk}}$

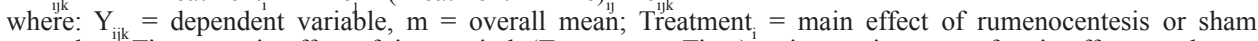

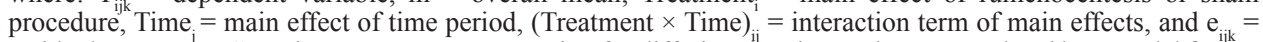
residual error term. Covariance structures accounting for differing time intervals were used and best model fit was determined by lowest indicator values for covariance structure. Where significant main effects were determined, pair-wise mean comparisons were determined by least significant difference method. Significance was determined at $\leq 0.05$, unless otherwise indicated. Data presented are least squared means $\pm \mathrm{SEM}$.

\section{Results}

None of the cows from group GA showed any resistance during rumen puncture and sampling. Physical examinations did not identify any clinical signs in cows of either 

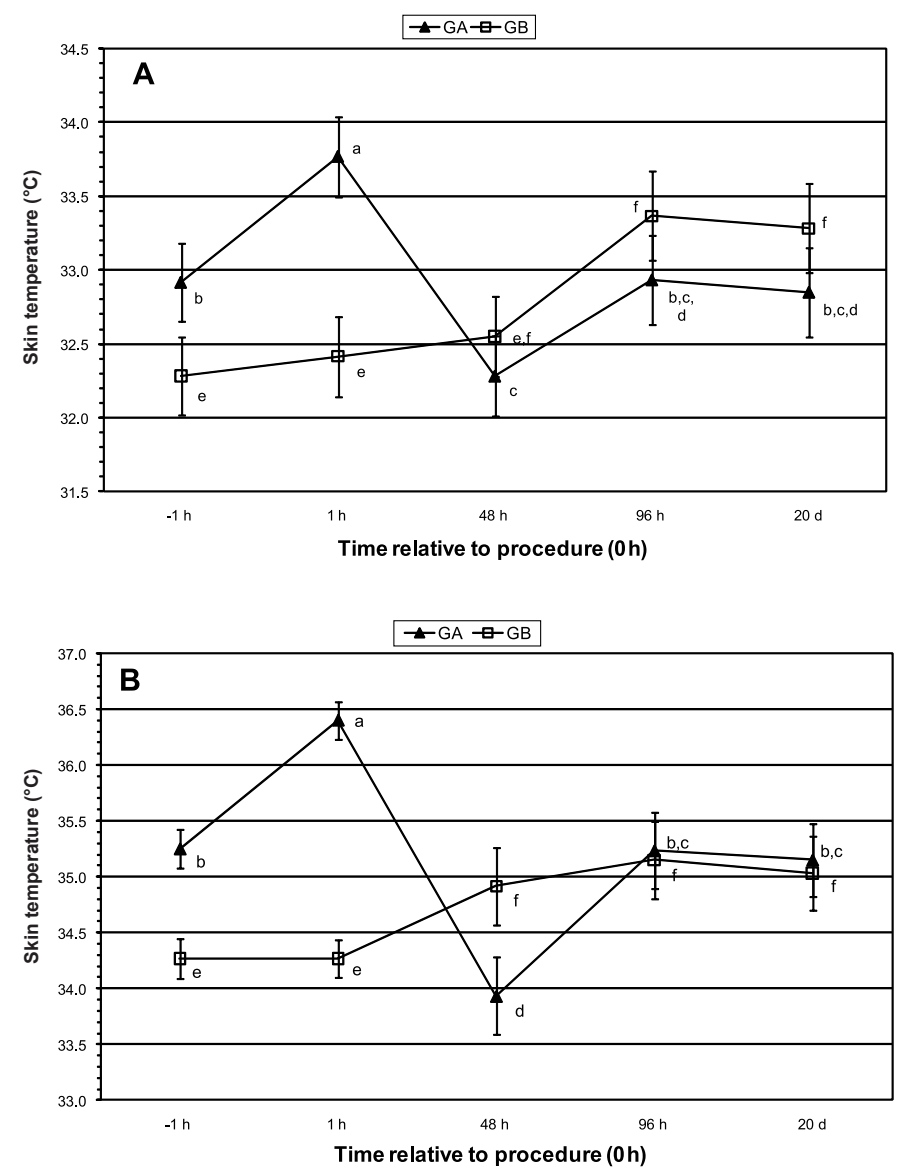

Fig. 1. Least squared means of average (A) and maximal (B) skin temperature $\left({ }^{\circ} \mathrm{C}\right)$ in cows at the site of rumenocentesis (GA) or sham procedure (GB). Means within treatment groups with different superscripts differ (A: ${ }^{\mathrm{a}, \mathrm{b}} P<0.0001 ;{ }^{\mathrm{a}, \mathrm{c}} P<0.001$; , ,d $P=0.1$; ${ }^{\mathrm{e}, \mathrm{f}} P<0.05 ; \mathrm{B}$ : ${ }^{\mathrm{a}, \mathrm{b}} P<0.0001 ;{ }^{\mathrm{a}, \mathrm{d}} P<0.0001$; ${ }^{\mathrm{b}, \mathrm{d}} P<0.001 ;{ }^{\mathrm{a}, \mathrm{c}} P<0.05$; ${ }^{\mathrm{c}, \mathrm{d}}$ $\left.P<0.05 ;{ }^{\text {eff }} P<0.05\right)$.

experimental group. Mean ( \pm standard deviation) rumen fluid $\mathrm{pH}$ in the GA group was $5.6 \pm 0.3$, with $50 \%$ (3 of 6 ) of the samples being less than $5.5 \mathrm{pH}$ units. Neither average nor maximal skin temperatures were influenced by the experimental group, although there was a group by time interaction $(P<0.0001)$. At the site of rumenocentesis average skin temperature in GA cows showed an increase of nearly $1.0^{\circ} \mathrm{C}$ immediately after the rumen fluid collection with a reduction at $48 \mathrm{~h}$ and stabilization to a normal level for the rest of study (Fig. 1A). In contrast, GB cows maintained a stable normal skin temperature for the whole study. A similar response over time was observed for maximal skin temperature (Fig. 1B). Rectal temperature was not different between groups at any time (Fig. 2).

Milk production was not different between experimental groups, but milk yield was influenced $(P=0.02)$ by the time period during the study (Fig. 3$)$. Average milk yield for cows in both groups was lower at $48 \mathrm{~h}(28.5 \mathrm{vs} .28 .3 \mathrm{~kg} / \mathrm{d}, P=0.03)$ and tended to be lower at $96 \mathrm{~h}(28.5 \mathrm{vs}$. $27.9 \mathrm{~kg} / \mathrm{d}, P=0.1$ ) compared to initial milk production. Milk yield in GA cows at $96 \mathrm{~h}$ was more variable. Although no differences were found in determining milk yield change between time 


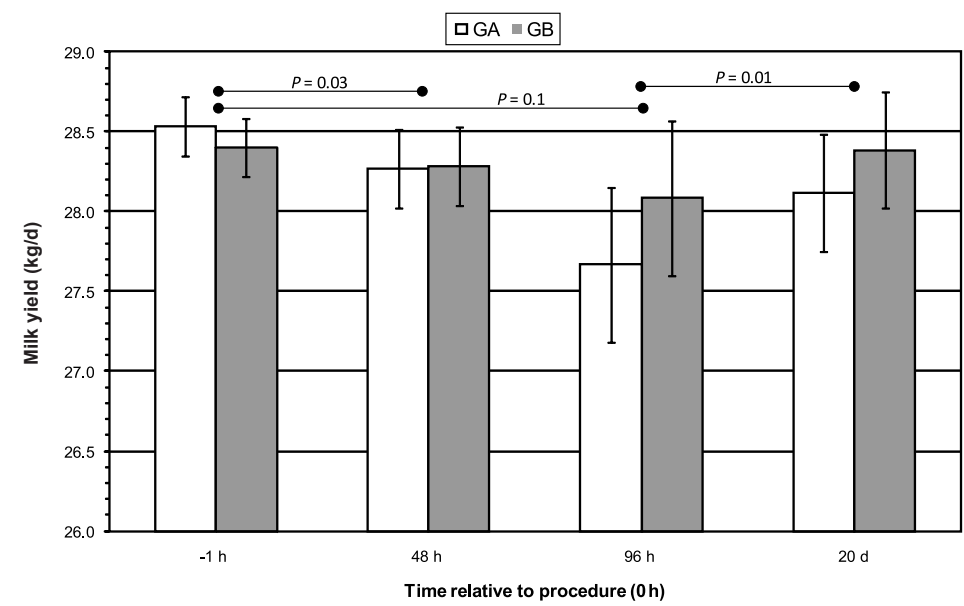

Fig. 2. Least squared means for milk yield in cows either undergoing rumenocentesis (GA) or sham (GB) procedure. There was no treatment effect; mean differences within time period are indicated above means.

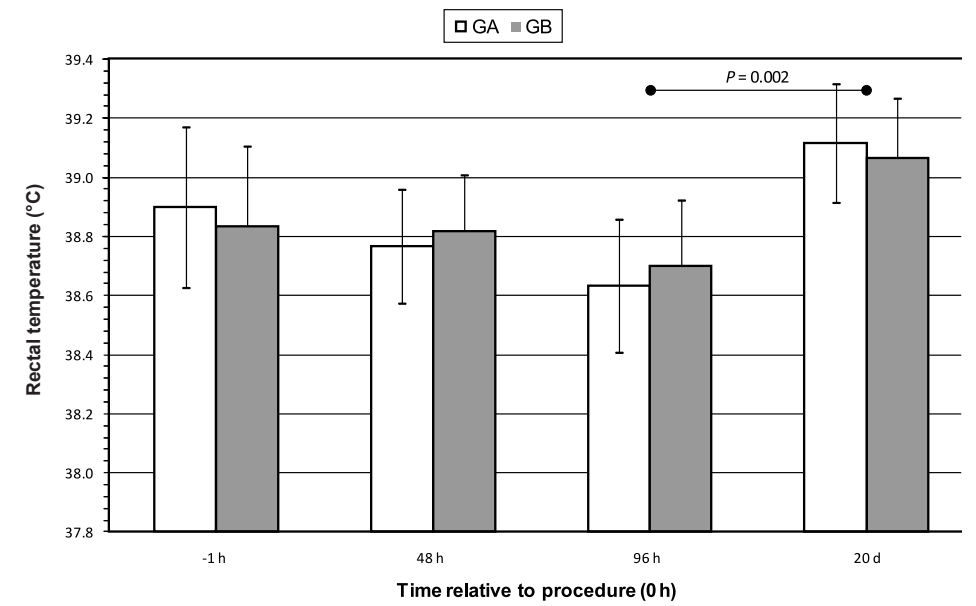

Fig. 3. Least squared means for rectal temperatures in cows either undergoing rumenocentesis (GA) or sham (GB) procedure. There was no treatment effect; mean differences by time period are indicated.

points or from reference point across groups, group GA cows showed a decline and a tendency for a decline in milk production from reference time $(28.5 \mathrm{~kg} / \mathrm{d})$ to $48 \mathrm{~h}(28.3 \mathrm{~kg} / \mathrm{d}, P=.04)$ and $96 \mathrm{~h}(27.7 \mathrm{~kg} / \mathrm{d}, P=0.08)$, respectively. In GA group cows only, milk yield at $20 \mathrm{~d}(28.1 \mathrm{~kg} / \mathrm{d})$ was greater $(P=0.03)$ compared to $96 \mathrm{~h}(27.7 \mathrm{~kg} / \mathrm{d})$.

All measured haematology, protein electrophoresis, and clinical chemistry variables are presented in Tables 1 and 2. Of all the variables measured, six were influenced by the procedure group and nearly half of the variables were influenced by the treatment by time interaction. Neutrophil count $(P=0.003)$, monocyte percent $(P=0.04)$, total $(P<0.0001)$ and direct $(P=0.01)$ bilirubin, haptoglobin $(P=0.03)$ and magnesium concentration $(P=0.02)$ were all influenced by the procedure group. For all comparisons by the procedure group, GB cows had higher mean values compared to GA cows with the exception of monocyte percentage. All values within each procedure group were considered to be within expected 


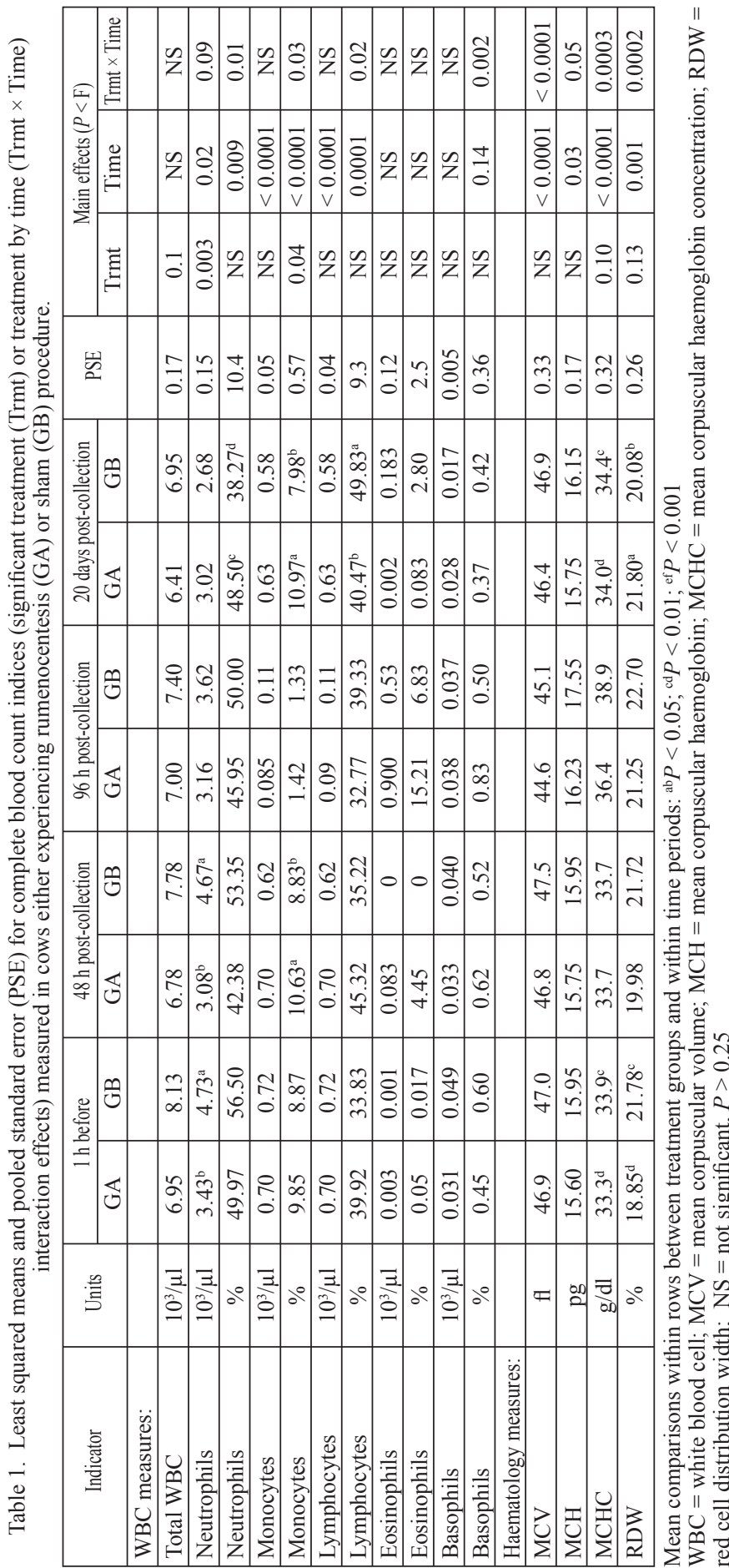

referencevalues (Kaneko et al. 1997). Absolute neutrophil cell counts at -1 and $48 \mathrm{~h}$ after rumenocentesis were greater $(P=0.03)$ in GB cows compared to GA cows (Fig. 4). Although there were a number of time $x$ treatment interactions that were significant, this interaction effect reflected differences in variable values changing over time within the procedure group with minimal significant difference between mean values at specific times.

\section{Discussion}

Concerns based on potential dietary risk factors for SARA in the sampled herd were confirmed with the rumen fluid $\mathrm{pH}$ analysis based on the diagnostic criteria of Oetzel (2004). These findings are consistent with previous studies (Kleen et al. 2004; Duffield et al. 2004) suggesting rumenocentesis to be a useful and valuable diagnostic tool in bovine medicine. Although the currentstudyusedalimited number of animals, the observed results provide preliminary evidence that would suggest minimal adverse local or systemic effects of performing rumenocentesis on the cows' health and production performance based on the scope of physiological variables measured. Additionally, 


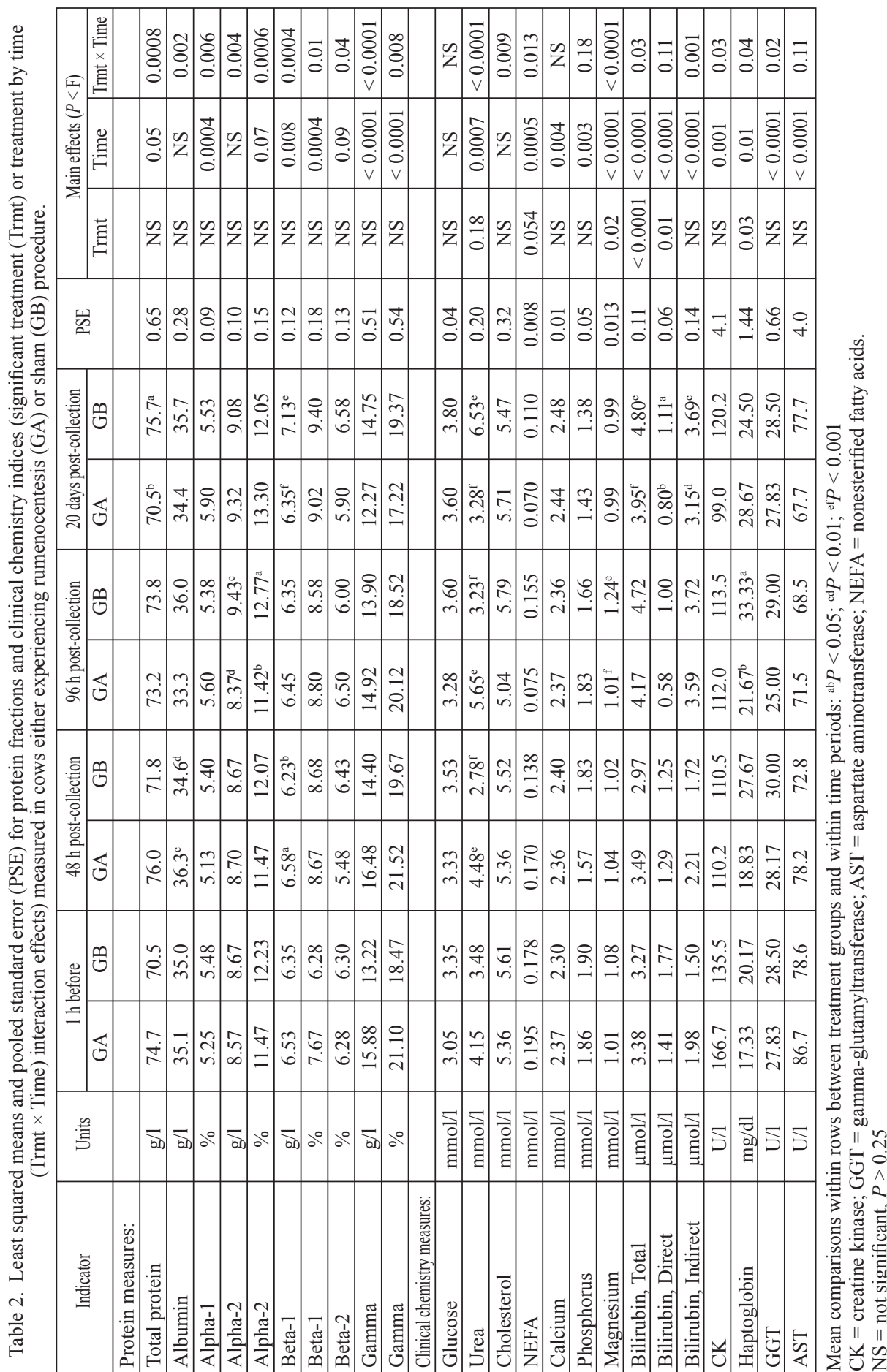




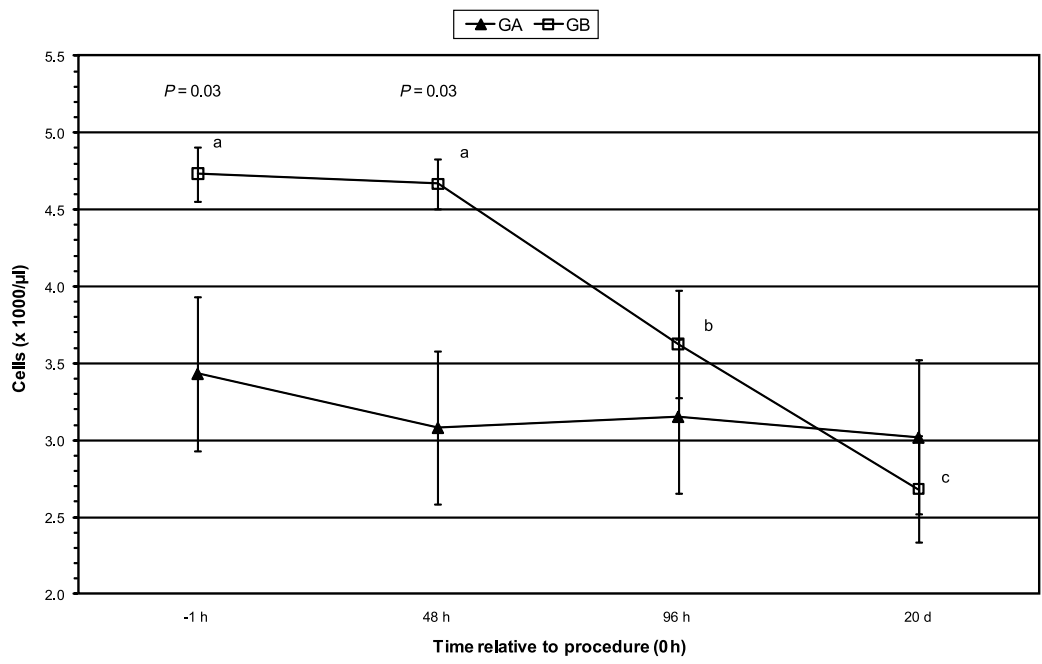

Fig. 4. Least squared means for neutrophil count in cows either undergoing rumenocentesis (GA) or sham (GB) procedure. Mean differences within time period are indicated with $P$ values. Mean differences within treatment group with different superscripts $\operatorname{differ}\left({ }^{\mathrm{a}, \mathrm{b}} P=0.1 ;{ }^{\mathrm{a}, \mathrm{c}} P=0.003 ;{ }^{\mathrm{b}, \mathrm{c}} P=0.01\right)$.

all cows tolerated the procedure as evidenced by physical behaviour responses suggesting minimal pain or discomfort. These findings are consistent with a previous study (Morgante et al. 2007) where a total of 120 cows were sampled, which reported no local or general problems following the procedure. Nevertheless, some authors have reported problems related to rumenocentesis such as abscesses and peritonitis (Hollberg 1984; Aceto et al. 2000; Strabel at al. 2007). Some authors consider rumenocentesis an invasive technique and veterinary practitioners often consider it too difficult to be used in routine clinical investigations. Rumenocentesis is considered an invasive technique involving surgical site preparation as well as physical and chemical restraint, thus placing the animal at risk for localized abscessation or peritonitis. Complications related to rumenocentesis may include some local inflammation with a subsequent increase in temperature at the site of the rumenocentesis. Observed skin temperatures (average and maximal) on the rumenocentesis area increased (not significantly) $1.0^{\circ} \mathrm{C}$ immediately after rumen fluid collection. Most likely this increase in GA cows is related to the manual procedure during rumenocentesis. In effect, already $24 \mathrm{~h}$ after rumenocentesis the temperature returned to the initial level and remained constant for the remaining period of the study. Moreover, daily milk productions were recorded to verify that rumenocentesis did not decrease production, although there was some suggestion of reduced milk yield at 96 $\mathrm{h}$ in the cows experiencing rumenocentesis. Further study with a larger number of animals would be necessary to determine if this temporal change is truly significant. Measures of blood nonesterified fatty acid and cortisol concentrations might provide additional insights as to the cows' health and stress factors as they influence the cows' response to the procedure.

Rumenocentesis complications associated with abscess formation or generalised inflammation (peritonitis) would be indicated by variation in blood variables indicative of an immune response. A complete blood count is helpful in supporting the diagnosis of local inflammation. Unless the infection is completely isolated by a fibrous tissue capsule or is small in size relative to animal size, there will be a leukocytosis and an elevation of polymorphonuclear leukocytes in acute lesions or lymphocytes and monocytes in more chronic ones. A moderate anaemia is usual in chronic lesions, and mild proteinuria is common. In all the blood samples studied (Table 1), there were minimal significant 
differences between haematological indicators obtained from the cattle of the two treatment groups and all values were within expected reference ranges. We observed a greater value in neutrophil and lymphocyte percentage at 20 days after rumenocentesis in GA cows compared to GB cows, which may suggest minimal evidence of an inflammatory response. Nevertheless, all values were within expected reference ranges and absolute counts of neutrophils and lymphocytes were not significantly different.

Through electrophoresis different subpopulations of blood proteins can be distinguished. Modification in serum protein fraction concentrations is of special importance regarding animal welfare. Inflammatory conditions often result in electrophoretic protein separation alterations, especially the $\alpha$-globulin fractions. Inflammatory processes result in increased production of serum anti-inflammatory proteins such as $\alpha 1$-antitrypsin and $\alpha 2$-macroglobulin to adjust homeostatic environmental conditions. In addition, a high gamma-globulinaemia may be due to an active infection. For the duration of the current study, similar shifts in electrophoretic protein separation were observed in our study, particularly an increase of beta- 1 and globulin in GB compared to GA cows at 20 days after rumenocentesis. These differences were not related to the different treatments, but most likely were a result of factors that typically occur in early lactation (intensity of feed intake, high milk production) and can influence these variables. Similar differences in total and direct bilirubin at 20 days following the treatment procedure were observed with higher values in group GB, though all values were within expected reference ranges.

Haptoglobin is an acute phase glycoprotein synthesized by the liver in response to soluble mediators produced by activated white blood cells and macrophages. Under normal circumstances without an active cellular response it is absent or present at low concentrations in serum. Haptoglobin concentration significantly increases in response to problems of infection, inflammation, and immune disorders. In the current study a significant increase in haptoglobin concentration was not observed in GA cows where rumenocentesis was performed. This finding suggests that rumenocentesis, as used to diagnose subacute ruminal acidosis, has minimal negative impact on the health of lactating cows over the period for which these cows were observed (20 days).

Although nearly half of the measured blood variables were influenced by the treatment and by time interaction in our study, it is supposed that most of these observed responses were related to time relative to calving rather than treatment effects. These blood variables are greatly influenced by time relative to calving as evidenced by the highly significant effect of time found with most variables. Mean differences observed for serum urea concentrations are related to feed intake differences over time during the study observational period. The observed higher mean urea values for GA compared to GB cows might suggest greater feed intake and further substantiate minimal negative effects of the rumenocentesis procedure. Although the data from the current study are suggestive that minimal adverse effects are observed in cows for 20 days following rumenocentesis, additional research with more animals and continued monitoring is important to evaluate potential effect of invasive diagnostic tests on animal health.

\section{Acknowledgements}

This work was supported by the research fund of BEN-O-LAT project of the Italian Ministry of Agriculture and Forestal Politics.

\section{References}

Aceto H, Simeone AJ, Fergusson JD 2000: Effect of rumenocentesis on and productivity in dairy cows. J Dairy Sci 83: 40

Berry RJ, Kennedy AD, Scott SL, Kyle BL, Schaefer AL 2003: Daily variation in the udder surface temperature of dairy cows measured by infrared thermography: Potential for mastitis detection. Can J Anim Sci 83: 687-693

Duffield T, Plaizier JC, Fairfield A, Bagg R, Vessie G, Dick P, Wilson J, Aramini J, McBride B 2004: Comparison of techniques for measurement of rumen $\mathrm{pH}$ in lactating dairy cows. J Dairy Sci 87: 59-66 
Eddy AL, Van Hoogmoed LM, Snyder JR 2001: The role of thermography in the management of equine lameness. Vet J 162: 172-181

Edmonson AJ, Lean IJ, Weaver LD, Farver T, Webster G 1989: A body condition scoring chart for Holstein dairy cows. J Dairy Sci 72: 68-78

Enemark JM, Jørgensen RJ, Enemark PS 2002: Rumen acidosis with special emphasis on diagnostic aspects of subclinical rumen acidosis: A review. Vet Med Zoot 42: 16-29

Garrett EF, Pereira MN, Nordlund KV, Armentano LE, Goodger WJ, Oetzel GR 1999: Diagnostic methods for the detection of subacute ruminal acidosis in dairy cows. J Dairy Sci 82: 1170-1178

Hollberg W 1984: Comparative studies of rumen fluid samples obtained by using the Schambye-Sorensen sonde or by puncture of the caudoventral rumen sac. Dtsch Tierarztl Wochenschr 91: 317-320

Kaneko J, Harvey W, Bruss M 1997: Clinical Biochemistry of Domestic Animals, 5th edn. Academic Press, USA, Appendix

Kleen JL, Hooijer GA, Rehage J, Noordhuizen JP 2004: Rumenocentesis (rumen puncture): a viable instrument in herd health diagnosis. Dtsch Tierarztl Wochenschr 111: 458-62

Krause KM, Oetzel GR 2006: Understanding and preventing ruminal acidosis: A review. Anim Feed Sci Technol 126: $215-236$

Littell RC, Milliken GA, Stroup WW 1999: SAS System for Mixed Models. Cary, NC: SAS Institute, Inc, pp. $87-134$

Lusk JL, Norwood FB 2008: A survey to determine public opinion about the ethics and governance of farm animal welfare. J Am Vet Med Assoc 233: 1121-1126

Morgante M, Stelletta C, Berzaghi P, Gianesella M, Andrighetto I 2007: Subacute rumen acidosis in lactating cows: an investigation in intensive Italian dairy herds. J Anim Physiol Anim Nutr 91: 226-234

Nocek JE 1997: Bovine acidosis: Implications on laminitis. J Dairy Sci 80: 1005-1028

Nordlund KV, Garrett EF 1994: Rumenocentesis: a technique for collecting rumen fluid for the diagnosis of subacute rumen acidosis in dairy herds. Bovine Practitioner 28: 109-112

Oetzel GR 2004: Monitoring and testing herds for metabolic disease. Vet Clin North Am 20: 651-674

Rollin BE 1990: Animal welfare, animal rights and agriculture. J Anim Sci 68: 3456-3461

Schaefer AL, Cook N, Tessaro SV, Deregt D, Desroches G, Dubeski PL, Tong AK, Godson DL 2004: Early detection and prediction of infection using infrared thermography. Can J Anim Sci 84: 73-80

Schwartzkopf-Genswein KS, Stookey JM 1997: The use of infrared thermography to assess inflammation associated with hot-iron and freeze branding in cattle. Can J Anim Sci 77: 577-583

Spire MF, Drouillard JS, Galland JC, Sargeant JM 1999: Use of infrared thermography to detect inflammation caused by contaminated growth promotant ear implants in cattle. J Am Vet Med Assoc 215: 1320-1324

Strabel D, Ewy A, Kaufmann T, Steiner A, Kirchhofer M 2007: Rumenocentesis: a suitable technique for analysis of rumen juice $\mathrm{pH}$ in cattle? Schweizer Archiv für Tierheilkunde 149: 301-306

Thompson PB 2005: Animal agriculture and the welfare of animals. J Am Vet Med Assoc 226: 1325-1327

Turner TA 1991: Thermography as an aid to the clinical lameness evaluation. Vet Clin North Am Equine Pract 7: $311-338$ 